\title{
Sliding Friction of Steel Combinations
}

\author{
Mohammad A. Chowdhury ${ }^{*}$, , Dewan M. Nuruzzaman ${ }^{2}$, Md. Arefin Kowser ${ }^{1}$, Md. \\ MostafizurRahman ${ }^{1}$,Biplov K. Roy ${ }^{1}$, Soma Chakraborty ${ }^{1}$, Md. Didarul Islam ${ }^{1}$, \\ Md. Aktaruzzaman ${ }^{1}$ and Nurmohammad ${ }^{1}$
}

\author{
${ }^{I}$ Department of Mechanical Engineering, Dhaka University of Engineering and Technology, Gazipur, Gazipur-1700, \\ Bangladesh \\ ${ }^{2}$ Faculty of Manufacturing Engineering, University Malaysia Pahang, Malaysia
}

\begin{abstract}
Tribological characteristics of steel combinations are observed in this study using rotating tribometer. Experiments are done under different roughnesses ofpin slides on stainless steel disc for different operating conditionsCertain trends are obtained between friction and rubbing durations. During experiment, it is foundthat there are significant relationship between friction coefficient and operating parameters. In fact, at initial stage friction coefficients of tested material are increased at a particular level with time and finally the friction becomes steady for remaining investigation period. Studies indicate that lower values of friction are obtained with higher loads for SS 202 slides against different roughnesses ofmild steel counterface. Under similar conditions, higher values of frictions are found with higher values of sliding velocity. In addition to that, wear rates show higher values with higher load and velocity conditions. Tribological characteristics are varied for different roughnesses of pin materials under experimental ranges of two influencing prameters.
\end{abstract}

Keywords: Steel combinations, operating parameters. tribological properties.

\section{INTRODUCTION}

There are several parameters [1-9] which affects the friction coefficient significantly. Two influential parameters are considered for frictional variation of different materials under sliding or rolling contact. Materials in conjunction with surface films under deliberately used or artificially generated by environmental impact, in this case, frictional properties show different characteristicsin relation to normal load. Lower friction factors were recorded with high load conditions for previously investigated material combinations. More roughness level and a abrasive particles formation can be considered for important causes of friction reduction [10, 11]. Under very precise surface characteristics of materials under the load at micro level, lower values of friction coefficient are obtained [12,13]. In reality, frictional properties is no affected by speed, isapplicable only under certain operating conditions. Friction may show different trends of increasing or decreasing behavior with increased sliding velocity for various material couples. Metal strength suffers deteriorate condition in context oflow flash point materials in relation to high temperature rise under sliding contact of two materials. The change of material behavior and metal structure due to higher temperaturewhich may be responsible for improving or deterioratingthe characteristics of metals in engineering applications[13]. Considerable worse effect happens usually whenmaterials attain

*Address correspondence to this author at the Department of Mechanical Engineering, Dhaka University of Engineering and Technology, Gazipur, Gazipur-1700, Bangladesh; Tel: +88-01766589508; Fax: +880-2-9204701; E-mail: asadzmn2003@yahoo.com maximum temperature level and stress-strain properties reduces more quickly, and in this case diffusivity of temperature and creep properties are most dominant factors. This causes more adhesive force at contacts and ductile nature which results in increased friction [13]. At higher speeds,higher values offriction coefficient are reported because ofhigher adhesive force generated between disc and counterface material (pin).

From previous studies [14-17], it has been shown that frictional properties of materials indicated various trends of results for different operating conditions. Despite these aforementioned investigations, no clear relationships are yet to be found in context of two dominating conditions (load and speed) on friction factor of tested stainless steel at different roughnesses of mild steel counterface. In these points of view, an effort is made in this study to observe the influence of load and speed on the frictional phenomena of stainless steel for two types of roughness ofmild steel pin.Variation in case of friction with wear in process time for SS 202 is also observed in this study. In addition, wear rate of SS 202 are studied at main operating parameters mentioned earlier.

Now a days, existing industrial systems, stainless steelmild steel pairs are used mostly for sliding/rolling applications in which low friction is the most important concern. Considering these versatile tribological applications, SS 202-mild steel pairs under two types of surface conditions are chosen for this Investigation. It can be desired that the data obtained in this study can be used an authentic source for improving thedifferent concerned mechanical and tribological systems and mechanisms. 
The purpose of this study was to identify the tribological properties for a artificially generated surface conditions by machining operations. The purpose of this study was to realize the effectofimportant variable parameters on tribology of SS 202. Under the present study, the main concern was to realize and find out the way of understanding the role of operating parameters on surface conditions of test samples. The results of this work can be beneficial for practical implication of machine design and other mechanical concerned mechanisms.

\section{TEST RIG AND TEST CONDITIONS}

Rotating tribometer is used to evaluate the frictional characteristics of steel combinations.

Schematic diagram of this set up is mentioned in Fig. (1). The details description of the set up and measuring techniques were motioned in the previous literature [18].

The facilities incorporating this system or test rig in comparison with other commercially available system or setup are as follows:

(i) The commercially available setup has certain range of different operating parameters for conducting experiments but this fabricated setup can be used to vary any range of operating parameters by simple modifications as per industrial requirements.

(ii) Some modifications are already incorporated in the present system to generate external horizontal and vertical vibration at different frequency and amplitude to observe their effects on tribological properties of different materials but this is the limitation in case of commercially available tribometer. (iii) Different diameters of pin and disc materials can be used in this setup.

(iv) The whole setup was fabricated using stainless steel to resist corrosion or moisture effect and any measuring system can be incorporated with the present system.

The detailed test parameters and ranges are summarized in Table $\mathbf{1 .}$

Table 1. Test parameters andranges.

\begin{tabular}{|c|c|c|}
\hline SI. No. & Parameters & Operating Conditions \\
\hline \hline 1. & Normal Load & $10,15,20 \mathrm{~N}$ \\
\hline 2. & Sliding Velocity & $1,1.5,2 \mathrm{~m} / \mathrm{s}$ \\
\hline 3. & Relative Humidity & $70( \pm 5) \%$ \\
\hline 4. & Duration of Rubbing & 30 minutes \\
\hline 5. & Surface Condition & Dry \\
\hline 6. & Disc material & Stainless steel $202(\mathrm{SS} 202)$ \\
\hline 7. & Roughness of SS $202, \mathrm{R}_{\mathrm{a}}$ & $0.35-0.45 \mu \mathrm{m}$ \\
\hline 8. & Pin material & Mild steel \\
\hline 9. & $\begin{array}{c}\text { Roughness of } \\
\text { mild steel, } \mathrm{R}_{\mathrm{a}}\end{array}$ & $\begin{array}{c}\text { (a) Smooth counterface: about } 0.25 \mu \mathrm{m} \\
\text { (b) Rough counterface: about } 3.25 \mu \mathrm{m}\end{array}$ \\
\hline 10. & Constant frictional radius & $25 \mathrm{~mm}$ \\
\hline 11. & Cylindrical pin diameter & $6 \mathrm{~mm}$ \\
\hline 12. & $\begin{array}{c}\text { Repeatability } \\
\text { of each experiment }\end{array}$ & \begin{tabular}{c}
5 times (under identical conditions) \\
\hline
\end{tabular} \\
\hline
\end{tabular}

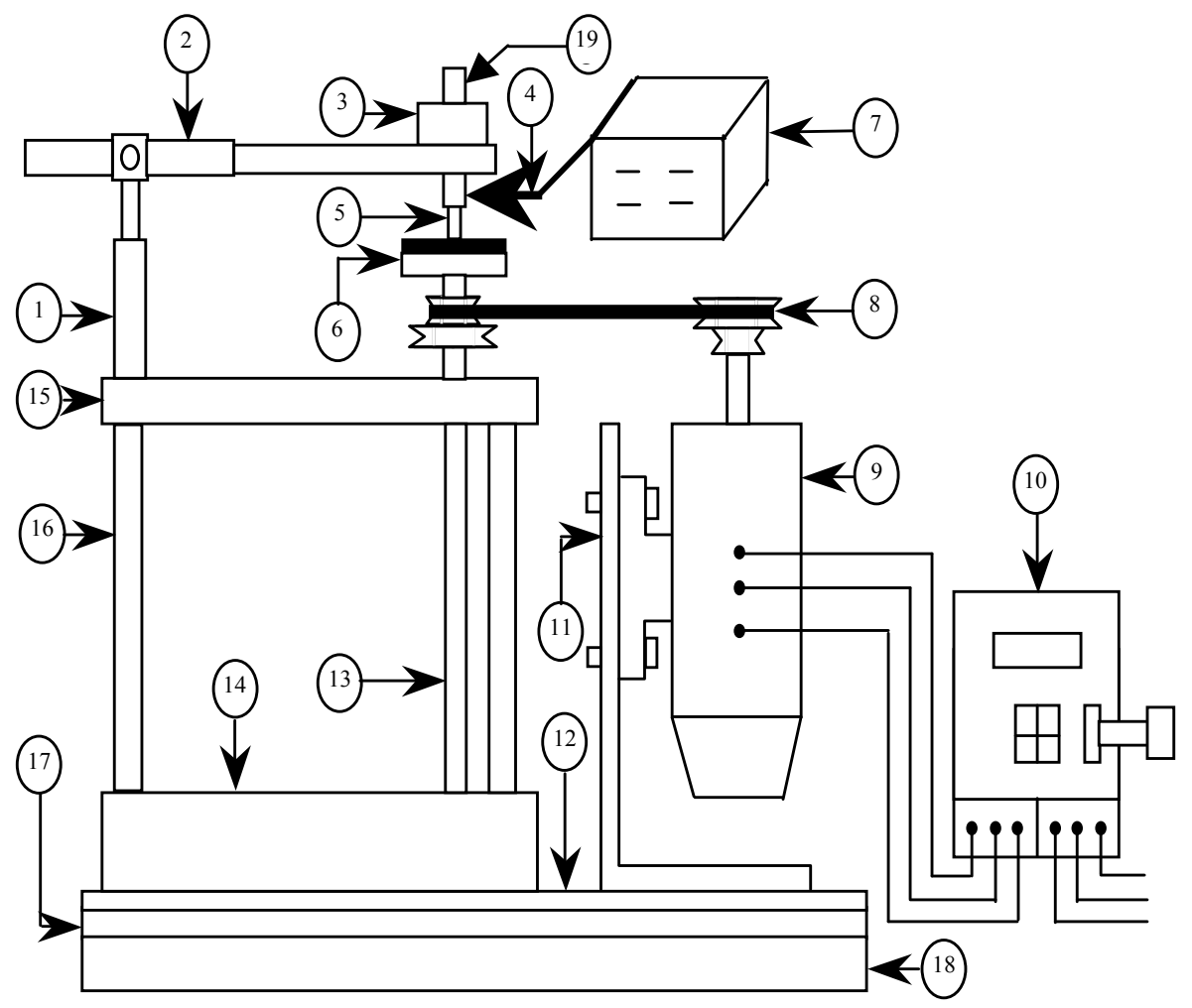

Fig. (1). Block diagram of the experimental set-up.
1 Load arm holder

2. Load arm

3. Normal load (dead weight)

4. Horizontal load (Friction force)

5. Pin sample

6. Test disc with rotating table

7. Load cell indicator

8. Belt and pulley

9. Motor

10. Speed control unit

11. Vertical motor base

12. $3 \mathrm{~mm}$ Rubber pad

13. Main shaft

14. Stainless steel base

15. Stainless steel plate

16. Vertical square bar

17. Mild steel main base plate

18. Rubber block (20 mm thick)

19. Pin holder. 


\section{RESULTS AND DISCUSSION}

\subsection{Frictional Characteristics with Time for Various Load Conditions}

Friction factors of SS 202 are affected by the wear in process time at tested applied loads when mating with smooth mild steel counterface (Fig. 2). The test conditions are mentioned in the figure. Curve 1 of this figure atlow load condition indicates at the beginningof wear in process, friction factor is 0.237 and then this value rises in a linear pattern to 0.282 . Wear in process of 20 minutes later,it remains constant for remaining observation period. Less amount of value is obtained at the beginning of test because of some foreign material layer on the surface of tested disc. This layer can be formed in relation to humidity factor, oxidation of metals,lubrication and other related particles. In case of starting of wear in process, film due to oxidation takes initiation to break the area of contact and as a consequence, deposition film deformed to create real metal to metal contact. The other considerable factors such as,ploughing formation, chip like abrasive metallic formation within the pin and disc impacting area and surface condition such as waviness, texture or roughness of test sample, increasedfrictional force generated with wear in process. Finally, the properties incorporating material loss processes are not changed with time and friction remains unchanged to maintain constant level.Similar trends are observed for curves 2 and 3 of this figure as that of curve 1 are expressed for mid and higher load range. The analysis of results confirm thatwear in process periods for unchanged constant level are not similar for observed applied loads. During friction process, for low, mid and high range of applied load, stainless steel-mild steel precise combinations are attained unchanged level at 20,17 and 14 minutes respectively. In fact, it can be realized that the applied load from low to high range, wear in process period to attain an unchanged level is small. The observations are in agreement with the observationofother researchers [19-21].

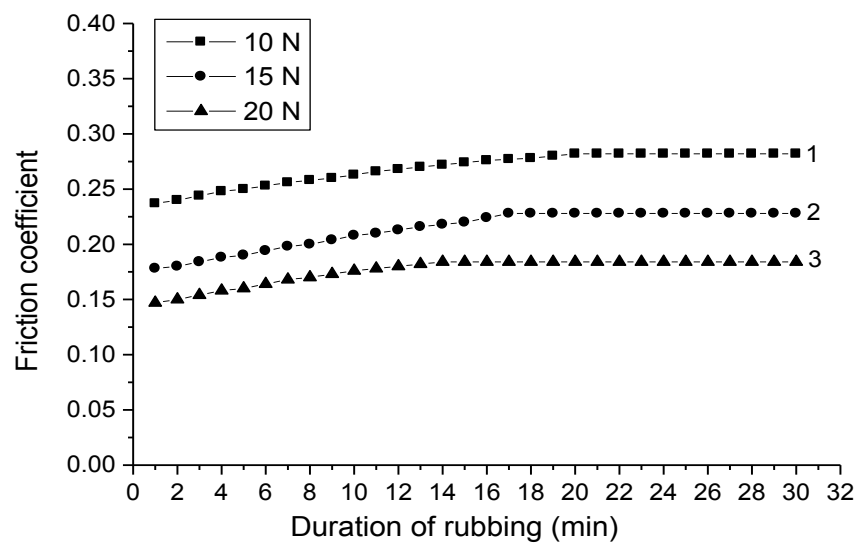

Fig. (2). Friction coefficient as a function of duration of rubbing at different normal loads (sliding velocity: $1 \mathrm{~m} / \mathrm{s}$, relative humidity: $70 \%$, test sample: SS 202, pin: mild steel,smooth).

The influence of wear in process period on friction factor under low to high range applied loads for stainless steel-mild steel rough counterface pairs at various test conditions mentioned in Fig. (3). Curve 1 for lower load, provides the data which informs that during the beginning of the test, friction factor is 0.294 which shows increased value of 0.333 at22 minutes and finally at the remaining test period that it maintainsunchanged level.Similar data patterns are found for mid and high range of applied loads. The time for unchanged friction conditions are almost identical which have been the mentioned in Fig. (2). In Fig. (3), it can be concluded that low to high range loads, 22, 19 and 15 minutes are required to attain the unchanged condition.

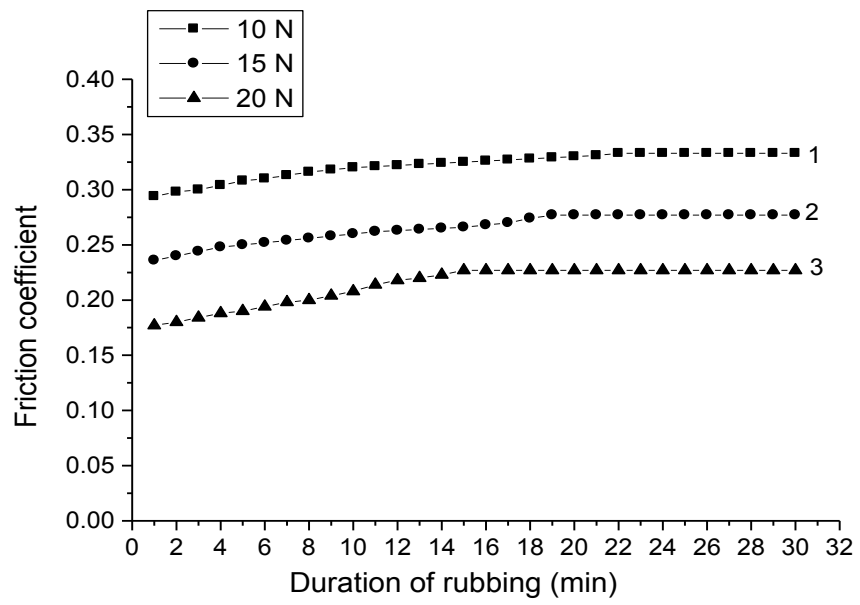

Fig. (3). Friction coefficient as a function of duration of rubbing at different normal loads (sliding velocity: $1 \mathrm{~m} / \mathrm{s}$, relative humidity: $70 \%$, test sample: SS 202, pin: mild steel,rough).

\subsection{Influence of Normal Load on Friction Coefficient}

Several experiments are done to find the relationship between friction factor and load in case of SS 202 contacting with precise or non precise mild steel pin. These results are indicated in Fig. (4). Friction factor changes from 0.282 to 0.184 and 0.333 to 0.227 with lower to higher loads for stainless steel -mild steel precise and stainless steel-mild steel non precise counterface. The trends of these data patternsensure that frictional value reduces in connection of higher applied loads. More roughness level and a abrasive particles formation can be considered for important causes of friction reduction $[10,11]$ under higher loads. Similar data patterns are found for ferrous and steel combination [20]i.e. friction reduce with load. At identical conditions, friction coefficient of SS 202 contacting with precise pin surface are smaller in comparison with SS 202 contacting with non precise pin surface. Average roughness of SS 202 after friction test varied from 1.02-1.27 and 1.25-1.45 $\mu \mathrm{m}$ for precise and non precise surface conditions.

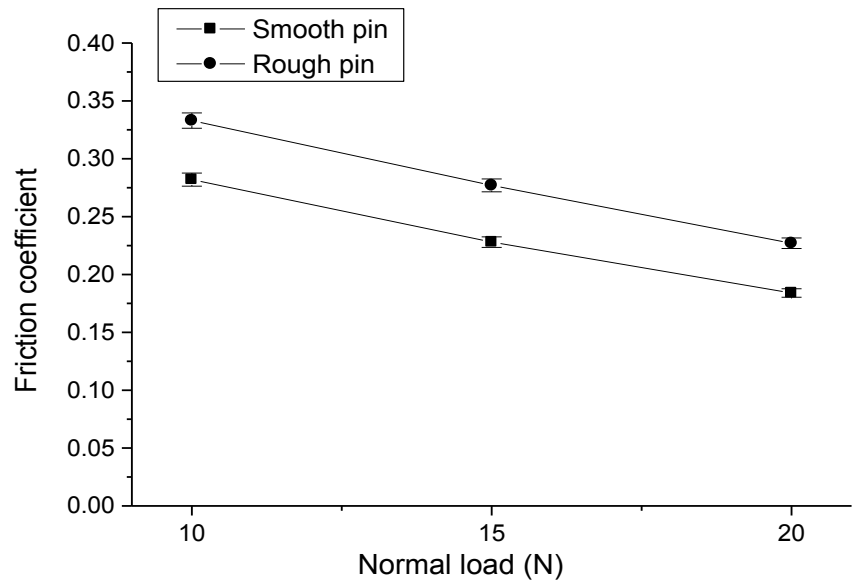

Fig. (4). Friction coefficient as a function of Normal load for SS 202 (Sliding velocity: $1 \mathrm{~m} / \mathrm{s}$, relative humidity: 70\%). 


\subsection{Frictional Characteristics with Time for Various Speed Conditions}

The relationship between friction factor and wear in process period at lower to higher speeds for stainless steel-mild steel precise pair and stainless steel-mild steel non precise pair accordinglyare shown in Figs. (5,6). During experiment, particular test conditions are maintained. The lower to higher velocity ranging from 1 to $2 \mathrm{~m} / \mathrm{s}$ are adjusted for test. Usually under lower velocity condition,at early stage, frictional value is low (0.178) and with wear in process period frictional value rises to 0.228 at the time of 17 minutes of wearing out and later the unchanged frictional values are observed. These patterns of increment can be related directly roughness changing phenomena with wearing out period as well as ploughing formation on test sample. During the wear in process after certain time period the parameters (roughness, temperature, chip formation etc.) affects the surface conditions to maintain the similar frictional level.The higher the velocity, the higher the frictional values are obtained.For unchanged frictional level, 17, 14 and 11 minutes are required for sliding velocities ranging from lower to higher value.Almost similar trends of data pattern with the wearing out period are confirmed in Fig. (6). Obviously, the magnitudes of frictional value are not similar for stainless steel-mild steel non precise combination.

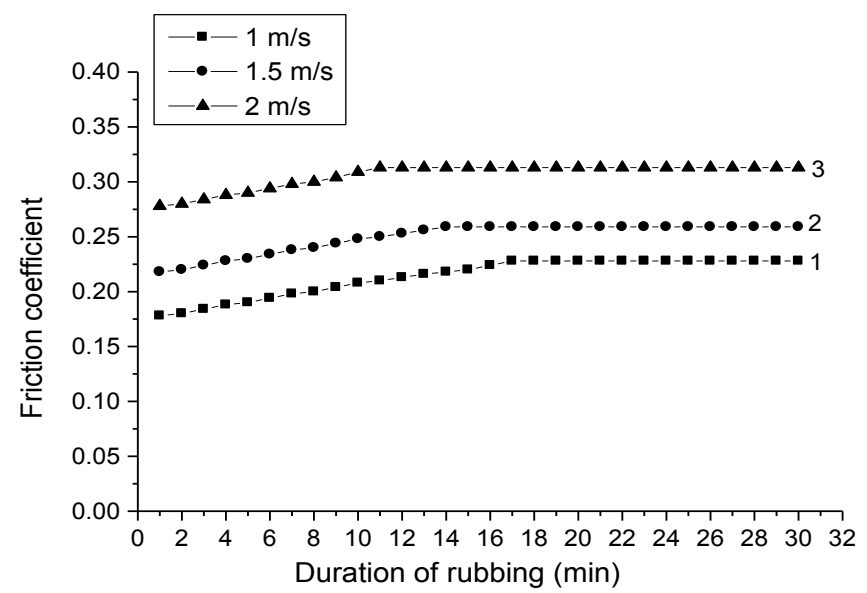

Fig. (5). Friction coefficient as a function of duration of rubbing at different sliding velocities (normal load: $15 \mathrm{~N}$, relative humidity: $70 \%$, test sample: SS 202, pin: mild steel,smooth).

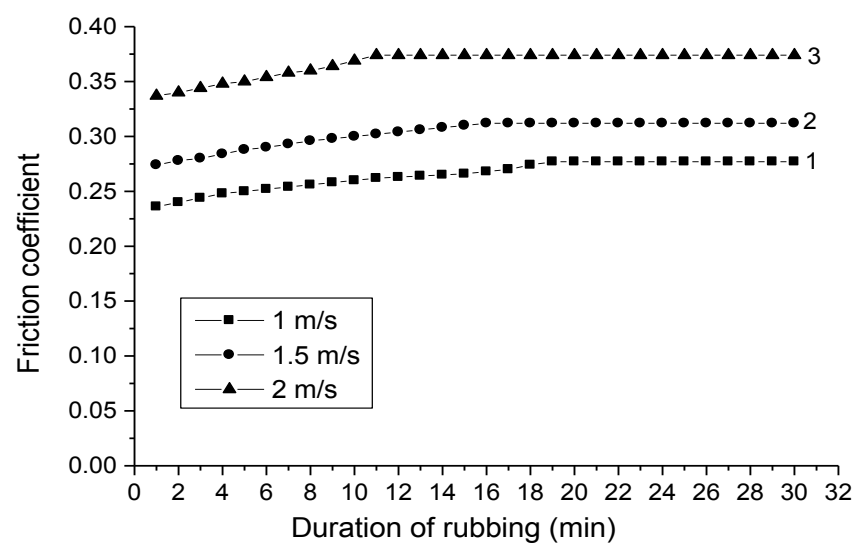

Fig. (6). Friction coefficient as a function of duration of rubbing at different sliding velocities (normal load: $15 \mathrm{~N}$, relative humidity: $70 \%$, test sample: SS 202, pin: mild steel,rough).

\subsection{Sliding Speed as a Function of Friction Coefficient}

The comparisons of frictional value with speed for the stainless steel mild steel precise or non precise combinations are shown in Fig. (7). Results indicate that frictional value changes from 0.228 to 0.313 and 0.277 to 0.374 with speed ranging from lower to higher value in context of stainless steel-mild steel precise and SS 202-mild steel non precise combinations. This means, friction factor shows higher value withhigher speed. Heat is generated at the asperities for the results of sliding contact of two materials and this causes high thermal condition at the contacting zone of two material combinations. More amount of adhesive force generation within the contacting point of fixed and rotating material [9]. At identical conditions, frictional value of stainless steelmild steel precise combination are smaller than that of stainless steel-mild steel non precise combination. The average roughness of SS 202 after 30 minutes run-in time varied from 1.08-1.32 and 1.35-1.51 $\mu \mathrm{m}$ for precise and non precise surface conditions.

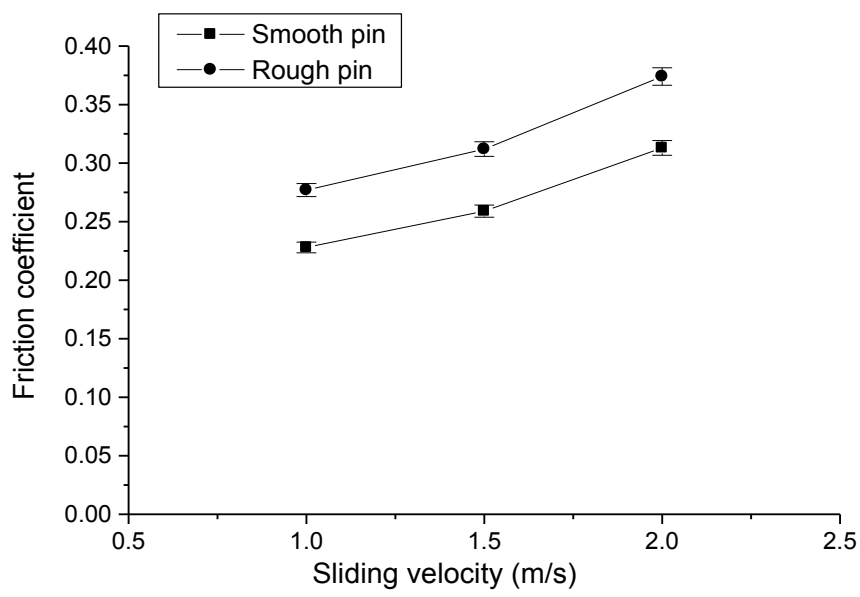

Fig. (7). Friction coefficient as a function of sliding velocity for SS 202 (normal load: $15 \mathrm{~N}$, relative humidity: 70\%).

\subsection{Applied Load in Context Material Loss}

Material loss changes in relation to loads and the data patterns of wearing out material aresummarized in Fig. (8). Wear rate of stainless steel 202 changes from 1.8 to 3.45 and 2.53 to $4.15 \mathrm{mg} / \mathrm{min}$ with lower to higher loads for precise and non precise surface conditions of mild steel. For both type of material couples, material loss shows higher value with higher loads. In fact, application of higher load at the upper end of the pin, the real area of contact are enlarged through the nominal area of contact and causes more tangential force within the impact surfaces. The more potential tangential thrust and shear force in conjunction with contacting real area accelerated more material loss. Almost nearest data patterns are analyzed earlier for metal-metal combinations [22] for abrasive material loss. At identical conditions, of stainless steel in connection with precise surface exhibits smaller material loss in comparison with stainless steel-non precise surface. In general, non precise surfaces wear out more rapidly which results in more friction than precise surfaces.

\subsection{Sliding Speed in Context of Material Loss}

Material losses are directly related with speed and the reflection of results has been summarized in Fig. (9). The 
realization form the figure is that material loss changes in the range of 2.6 to 4.73 and 3.33 to $5.57 \mathrm{mg} / \mathrm{min}$ for lower to higher speed particularly stainless steel-mild steel precise and stainless steel-mild steel non precise combinations. This means, material losses are accelerated more with more speed of two types of combinations. In general sense, wearing out period is same for low, mid and high speed, while the sliding distance are morefor larger speed. The reduction of shearing strength of metals due to thermal effect and enhanced of true area of contact within contacting surfaces of mating materials may cause more abrasive material loss with speed [9]. At identical conditions, lower level of wearing out are realized for stainless steel- precise surface in comparison of stainless steel-non precise surface.

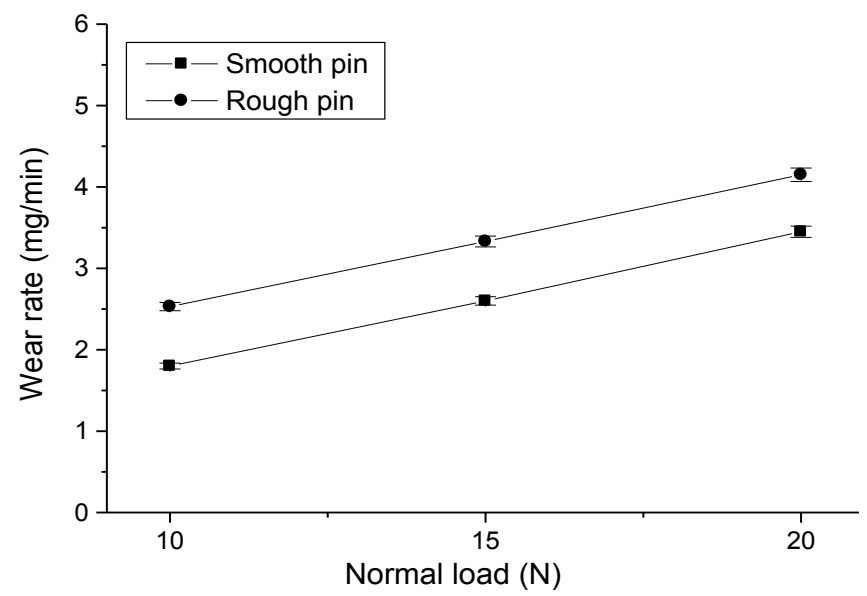

Fig. (8). Wear rate as a function of Normal load for SS 202 (Sliding velocity: $1 \mathrm{~m} / \mathrm{s}$, relative humidity: $70 \%$ ).

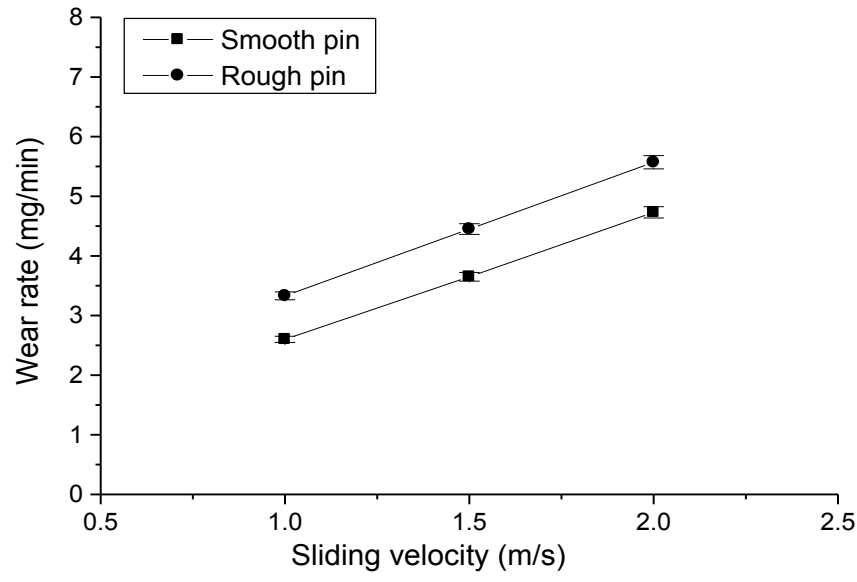

Fig. 9: Wear rate as a function of sliding velocity for SS 202 (normal load: $15 \mathrm{~N}$, relative humidity: $70 \%$ )

Fig. (9). Wear rate as a function of sliding velocity for SS 202 (normal load: $15 \mathrm{~N}$, relative humidity: 70\%).

\subsection{A Comparison of Other Sliding Wear Test Methods with Pin-on-Disc Wear Test}

Generally, friction stir welding method is considered to focus on metal joining. Linear and rotational are obtained for friction stir welding pin tool.The linear movement of the tool through the materials to be joined, it generates heat due to the friction between the tool and the components. Material loss of tool is a major concern for this process. The radial loss of material exhibits various data pattern atdesigned distance of pin, and the maximum material loss is produced particularly about one-third pin length from the pin root. The welding speed as a function of radial material loss of the pin, and the highest amount ofmaterial loss is initiated during earlier period of welding [23].

Tool wear characteristics in friction stir drilling are quantified by measuring its weight change at different depend on spindle speeds, feed rates, drill diameters, part thickness, tool shape and mass $[24,25]$. In our research works, investigations were carried out to observe the effect of speed and load on sliding wear as well as friction in context of stainless steel 202 against Smooth and Rough Mild Steel Counterfaces by using pin-on-disc machine. In some cases, micro-welding may be generated due to the interaction of disc and pin materials and heat may be generated at high loads and sliding velocities.

In this research, the method adopted was quite different in nature in comparison with friction stir welding or friction drilling. But in case of wear measurement or properties, in future some correlations may be established between the wear rate in the present study with the tool wear in the friction stir welding or friction drilling. The results obtained from this investigation can be used as a valuable source for researchers and industry to design mechanisms or systems and create the opportunity for using these materials combinations under tested normal load, sliding velocity and surface conditions in context of tribological issues.

\section{CONCLUSION}

Normal load and sliding velocity and different roughnesses of counterface material has significant effect on tribological propertiesof steel materials. The higher the applied loads, the higher the friction factorsare recorded.On the other hand, friction coefficients show reverse trendsfor sliding velocity in case of SS 202 for smooth or rough mild steel pin counterface. There is a relationship between friction and wearing out period. At early stage friction coefficient increases first and extending with the wearing time, friction factor reaches to the unchanged level. Wear rates of SS 202 for smooth or rough mild steel counterface isincreased with higher value of load and speed. Friction factor and materialloss of stainless steel for smooth counterface are lower in comparison with stainless steel forrough counterface at similar conditions.

As a matter of fact the frictional resistance and material loss of SS 202 strongly depends on the test conditions for different roughnesses of counterface pins, therefore selecting a suitable test parameters and preferable surface roughness of metals, friction and wear to maintain desirable range for proper mechanical design of different concerned mechanical and tribological systems in industry.

\section{CONFLICT OF INTEREST}

The authors confirm that this article content has no conflict of interest.

\section{ACKNOWLEDGEMENTS}

The authors wish to thank Dhaka University of Engineering and Technology, Gazipur, Bangladesh for the technical and financial support to complete the research work. 


\section{REFERENCES}

[1] J. F. Archard, Wear Theory and Mechanisms, Wear Control Handbook, M. B. Peterson and W.O. Winer, eds., ASME, New York, NY, pp. 35- 80, 1980.

[2] D. Tabor, "Friction and Wear - Developments over the last 50 Years", Keynote Address, Proc. International Conf. Tribology Friction, Lubrication and Wear, 50 Years On, London, Inst. Mech. Eng., 1997, pp. 157-72.

[3] S. T. Oktay, and N. P. Suh, "Wear debris formation and agglomeration", ASME Journal of Tribology, vol. 114, pp. 379-93, 1992.

[4] N. Saka, M. J. Liou, and N. P. Suh, "The role of tribology in electrical cotact phenomena", Wear, vol. 100, pp. 77-105, 1984.

[5] N. P. Suh, and H. C. Sin, "On the genesis of friction and its effect on wear", solid contact and lubrication", H. S. Cheng and L. M. Keer, ed., ASME, New York, NY, AMD-vol. 39, pp. 167-83, 1980.

[6] J. W. Lin, and M. D. Bryant, "Reduction in wear rate of carbon samples sliding against wavy copper surfaces", ASME Journal of Tribology, vol. 118, pp. 116-24, 1996.

[7] K. C. Ludema, Friction, Wear, Lubrication a Textbook in Tribology, CRC press, London, UK. 1996.

[8] E. J. Berger, C. M. Krousgrill, and F. Sadeghi, "Stability of sliding in a system excited by a rough moving surface", $A S M E$, vol. 119, pp. $672-80,1997$.

[9] B. Bhushan, Principle and applications of tribology, John Wiley \& Sons, Inc., New York, 1999.

[10] B. Bhushan, "Tribology and Mechanics of Magnetic Storage Devices", 2nd edition, Springer-Verlag, New York, 1996.

[11] P.J. Blau, "Scale Effects in Sliding Friction: An Experimental Study", In: Fundamentals of Friction: Macroscopic and Microscopic Processes, vol. E220, I.L., Singer and H. M., Pollock, eds., Kluwer Academic, Dordrecht, Netherlands, 1992, pp. 523-34.

[12] B. Bhushan, Handbook of Micro/ Nanotribology, 2nd edition, CRC Press, Boca Raton, Florida, 1999

[13] B. Bhushan, and A. V. Kulkarni, "Effect of normal load on microscale friction measurements", Thin Solid Films, vol. 278,pp. 49-56, 1996.

[14] M. A. Chowdhury, and M. M. Helali, "The effect of relative humidity and roughness on the friction coefficient under horizontal vibration", The Open Mechanical Engineering Journal, vol. 2, pp. 128- 35, 2008.

[15] M. A. Chowdhury, M. M. Helali, and A.B.M. Toufique Hasan, "The frictional behavior of mild steel under horizontal vibration", Tribology International, vol. 42, pp. 946- 950, 2009.

[16] M. A. Chowdhury, S. M. I. Karim, M. L. Ali, "The influence of natural frequency of the experimental set-up on the friction coefficient of copper", In: Proc. of IMechE, Journal of Engineering Tribology, vol. 224, pp. 293- 298, 2009.

[17] M. A. Chowdhury, D. M. Nuruzzaman, M. L. Rahaman, "Influence of external horizontal vibration on the coefficient of friction of aluminium sliding against stainless steel", Industrial Lubrication and Tribology, vol. 63, pp. 152- 157, 2011.

[18] D.M. Nuruzzaman, M.L. Rahaman, and M.A. Chowdhury, "Friction coefficient and wear rate of polymer and composite materials at different sliding speeds" International Journal of Surface Science and Engineering, vol. 6, pp. 231-45, 2012.

[19] M. A. Chowdhury, and M. M. Helali, "The effect of frequency of vibration and humidity on the coefficient of friction", Tribology International, 39, pp. 958-62, 2006.

[20] M. A. Chowdhury, and M. M. Helali, "The Effect of amplitude of vibration on the coefficient of friction", Tribology International, 41, pp. 307- 14, 2008

[21] M. A. Chowdhury, M. K. Khalil, D. M. Nuruzzaman, and M. L. Rahaman, "The effect of sliding speed and normal load on friction and wear property of Aluminum", International Journal of Mechanical \& Mechatronics Engineering, vol. 11, pp. 53-7, 2011.

[22] M. A. Chowdhury, and M. M. Helali, "The effect of frequency of vibration and humidity on the wear rate", Wear, vol. 262, pp. 198203, 2007.

[23] H.J. Liu, J.C. Feng, H. Fujii, and K. Nogi, "Wear characteristics of a $\mathrm{WC}-\mathrm{Co}$ Tool in friction stir welding of $\mathrm{AC} 4 \mathrm{AC} 30 \mathrm{vol} \% \mathrm{SiCp}$ Composite", International Journal of Machine Tools \& Manufacture, vol. 45, pp. 1635-9, 2005.

[24] S.F. Miller, P. J. Blau, and A. J. Shih, "Tool wear in friction drilling ", International Journal of Machine Tools \& Manufacture, vol. 47, pp. 1636-45, 2007.

[25] A. Fernández, L. N. Lopez de Lacalle, and A. Lamikiz, "Friction drilling of stainless steels pipes", American Institute of Physics, Conf. Proc., 2010, vol. 1345, pp. 1187-92, ISBN: 978-0-73540871-5.

(c) Chowdhury et al.; Licensee Bentham Open.

This is an open access article licensed under the terms of the Creative Commons Attribution Non-Commercial License (http://creativecommons.org/licenses/ by-nc/3.0/) which permits unrestricted, non-commercial use, distribution and reproduction in any medium, provided the work is properly cited. 